\title{
Conversion of palm oil to new sulfur-based polymer by inverse vulcanization
}

\author{
Amin Abbasi ${ }^{1}$, Mohamed Mahmoud Nasef $^{2}$, Wan Zaireen Nisa Yahya ${ }^{1,3^{*}}$, and Muhammad Moniruzzaman ${ }^{1}$ \\ ${ }^{1}$ Chemical Engineering Department, Universiti Teknologi PETRONAS, 32610 Seri Iskandar, Perak, Malaysia. \\ ${ }^{2}$ Malaysia Japan International Institute of Technology, Universiti Teknologi Malaysia, 54100 Kuala Lumpur, Malaysia. \\ ${ }^{3}$ Centre of Research in Ionic Liquids, Universiti Teknologi PETRONAS, 32610 Seri Iskandar, Perak, Malaysia.
}

\begin{abstract}
The conversion of palm oil into a sulfur-based polymer by copolymerization with sulfur powder at its molten state is herein reported. The obtained sulfur-containing polymer was characterized using Fourier transform infrared (FTIR), thermogravimetric analysis (TGA), and differential scanning calorimetry (DSC) to demonstrate the successful conversion. The disappearance of the peaks related to vinylic groups of oil together with the appearance of a peak representing $\mathrm{C}-\mathrm{H}$ rocking vibrations in the vicinity of C-S bonds confirmed the copolymerization of sulfur with oil. TGA revealed that the polymers have thermal stability up to $230^{\circ} \mathrm{C}$ under nitrogen and the polymers leave $10 \%$ sulfur-rich ash. DSC proved that a small amount of elemental sulfur remained unreacted in the polymer, which showed amorphous and heavily crosslinked structure resembling thermosets. These copolymers are an environmental-friendly polymeric material promoting the utilization of the abundant sulfur while also adding value to palm oil.
\end{abstract}

\section{Introduction}

Nowadays, the rapid technological development and the ever-increasing dependency on petro-based polymers posing serious disposal challenges to both human life and environment are attracting growing attention $[1,2]$. Biopolymers, in general, have shown significant potential as replacements for petro-based polymers since they are able to reduce the environmental effects of conventional polymers while offering a lower price [3].

Vegetable oils are an abundant and cheap class of materials that have shown great potential to react as monomers to produce biopolymers. Polymers made from vegetable oils are used in different applications such as food packaging, polymeric composites, medical devices, insulators, adhesives, and plasticizers [4-6]. More information on different polymers made from vegetable oils and their versatile applications can be found elsewhere [6]. Palm oil is a readily available vegetable oil in Malaysia and Indonesia both of which produce about 86 percent of the world's palm oil production annually $[7,8]$. According to the Malaysian Palm Oil Council (MPOC), only in 2019 about 18,469,258 MT of palm oil was exported from Malaysia and thus, finding a new application of high interest to overcome the declining demand for this oil from EU countries can help to develop the domestic palm oil industry [9].

The idea of using palm oil to produce green polymers was motivated by the presence of an unsaturated portion of triglycerides that makes them suitable for polymerization or copolymerization with other monomers [10]. A typical composition of palm oil is shown in Table 1 [8]. However, it must be mentioned that the composition percentages may vary in different palm species and also the growing conditions of the vegetable [11]. Oleic, linoleic, and linolenic acids are the most important unsaturated fatty acid constituents and it can be observed that almost 50 percent of palm oil is made of molecules with $\mathrm{C}=\mathrm{C}$ double bonds [8].

Table 1. Typical fatty acid composition of palm oil [8]

\begin{tabular}{|c|c|c|}
\hline Fatty acid & $\begin{array}{c}\text { Number of C atoms: } \\
\text { Number of C=C bonds } \\
\text { (C:D) }\end{array}$ & $\begin{array}{c}\text { Percentage } \\
\text { in palm oil }\end{array}$ \\
\hline Oleic acid & $18: 1$ & 39.2 \\
\hline Linoleic acid & $18: 2$ & 10.1 \\
\hline Linolenic acid & $18: 3$ & 0.4 \\
\hline Palmitic acid & $16: 0$ & 44.0 \\
\hline Stearic acid & $18: 0$ & 4.5 \\
\hline Myristic acid & $14: 0$ & 1.1 \\
\hline Lauric acid & $12: 0$ & 0.2 \\
\hline Arachidic & & 0.1 \\
\hline
\end{tabular}

\footnotetext{
* Corresponding author: zaireen.yahya@utp.edu.my
} 


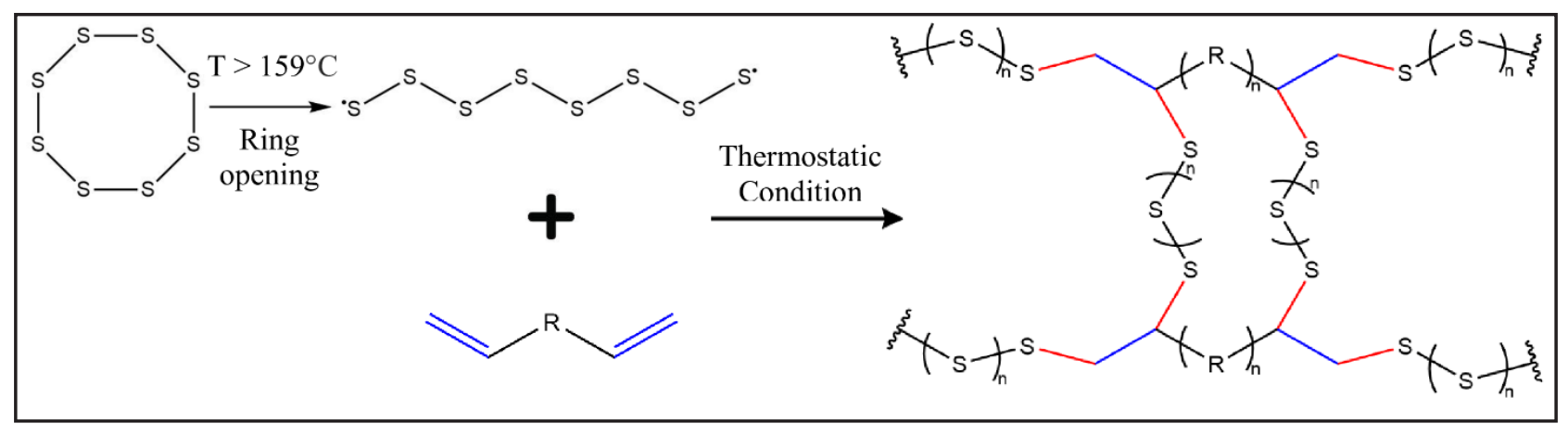

Fig. 1. General mechanism of inverse vulcanization [1].

Palm oil has already been investigated in some polymerization processes [12]. Kalita et al. [13] polymerized palm oil with 2-(vinyloxy) ethanol employing the base-catalyzed transesterification. In another study, Tajau et al. [14] studied new polymeric precursors as a low molecular weight drug delivery system by using palm oil to produce epoxidized palm olein and diol. In another study, Mas'ud et al. [15] polymerize waste palm cooking oil by cationic polymerization under microwave irradiation with boron trifluoride-etherate as a catalyst. The main problems with these procedures are the low conversion of the palm oil to polymeric material together with the necessity of catalysts and initiators [13-15].

Inverse vulcanization which was first introduced in 2013 is a technique that makes it practicable to copolymerize sulfur with one or more vinylic monomer(s) without the need of catalysts, initiators, and solvents $[16,17]$. Inverse vulcanization was first carried by reacting sulfur at molten state with petro-based monomers such as 1,3-diisopropenylbenzene (DIB) $[17,18]$.

Later on, some bio-based monomers such as limonene [19], diallyl disulfide [20], and squalene [21] and vegetable oils like rubber seed [22,23], sunflower, linseed, olive [24], canola [25], and soybean [26] oils showed potential to react with elemental sulfur by inverse vulcanization technique. The reactions of sulfur with various monomers both petro-based and bio-based and the properties of the obtained copolymers have been recently reviewed $[3,6]$.

The inverse vulcanization (molten state copolymerization) reaction proceeds by heating elemental sulfur to temperatures higher than its melting point at which the cyclic structure of sulfur opens and forms a diradical 8-atom linear structure of sulfur chain. The presence of a vinylic monomer with the sulfur melt initiates the polymerization process $[27,28]$. The general mechanism of the reaction of elemental sulfur and a vinylic monomer by an inverse vulcanization reaction is demonstrated in Figure 1 [3].

The objective of this study is to copolymerize sulfur with palm oil to form a new bio-based sulfur polymer via the inverse vulcanization technique. In the inverse vulcanization technique, the percentage of sulfur is set to be not less than 50 weight percent. The effect of different reactant ratios (sulfur: palm oil) on the sulfur conversion was investigated. Fourier Transform infrared spectroscopy (FTIR), thermogravimetric analysis (TGA), and differential scanning calorimetry (DSC) were then used to evaluate the properties of the obtained polymer.

\section{Experimental}

\subsection{Materials}

Refined palm oil was obtained from the Malaysian local suppliers and was utilized as received and elemental sulfur (99.9\% assay) powder was purchased from PC Laboratory Reagent, Malaysia.

\subsection{Preparation of the poly (S-Palm oil)}

Different wt\% of sulfur to oil ratios (50:50, 60:40, 70:30, and 80:20) were used as reactants. In each selected percent composition, elemental sulfur was first melted by continuous heating from room temperature to $170^{\circ} \mathrm{C}$ in a glass vial using a thermostatic oil bath with continuous stirring. After a change in the color of molten sulfur from yellow to light orange showing the initiation of the ring-opening process, the palm oil was slowly added to the glass vial. The mixture was kept at $170^{\circ} \mathrm{C}$ for 1 hour under continuous stirring. After the reaction has completed, the samples were cooled at room temperature. It is noteworthy to mention that a range of reaction time and temperatures was initially screened and concluded that $170^{\circ} \mathrm{C}$ and 1 hour were found to be the best conditions to obtain visually uniform polymers.

\subsection{Characterization of the copolymers}

FTIR was performed using a PerkinElmer's Frontier model spectrophotometer model equipped with Universal ATR Accessory. TGA and DSC were used to investigate the thermal stability and thermal properties of the obtained polymers. A PerkinElmer STA 6000 thermal analyzer was employed to obtain thermograms under nitrogen atmosphere in a temperature range of 30$900^{\circ} \mathrm{C}$ at a heating rate of $10^{\circ} \mathrm{C} / \mathrm{min}$. DSC measurements were carried out using TA Instruments Q2000 model in the temperature ranging from -50 to $250^{\circ} \mathrm{C}$ under a nitrogen atmosphere with a heating rate of $10^{\circ} \mathrm{C} / \mathrm{min}$.

\section{Results and discussion}

By conducting some preliminary studies, it was found that polymers made by sulfur contents higher than 80 $\mathrm{wt} \%$ were not firm against depolymerization by time resulting in the conversion of sulfur chains back to elemental sulfur. Hence, $80 \mathrm{wt} \%$ was chosen as the 
highest sulfur content to produce S-Palm oil polymers that are firm against depolymerization.

\subsection{Conversion of sulfur to poly (S-Palm oil)}

Figure 2 shows the TGA thermograms for the S-Palm oil polymers with different initial feed ratios while Table 2 provides information on the experimental and calculated sulfur contents from TGA curves. The first weight loss can be attributed to the total sulfur content of the polymer [29]. The first weight loss percentage increases with increasing the initial elemental sulfur percentage from 50 to $80 \mathrm{wt} \%$ [24,30-32].

For all the obtained polymers, the difference between the sulfur content in the polymer (which can be calculated using the weight loss at the end of the first degradation step) and the initial sulfur content is less than $10 \%$ which suggests that most of the initial elemental sulfur has been converted into the polymeric structure.

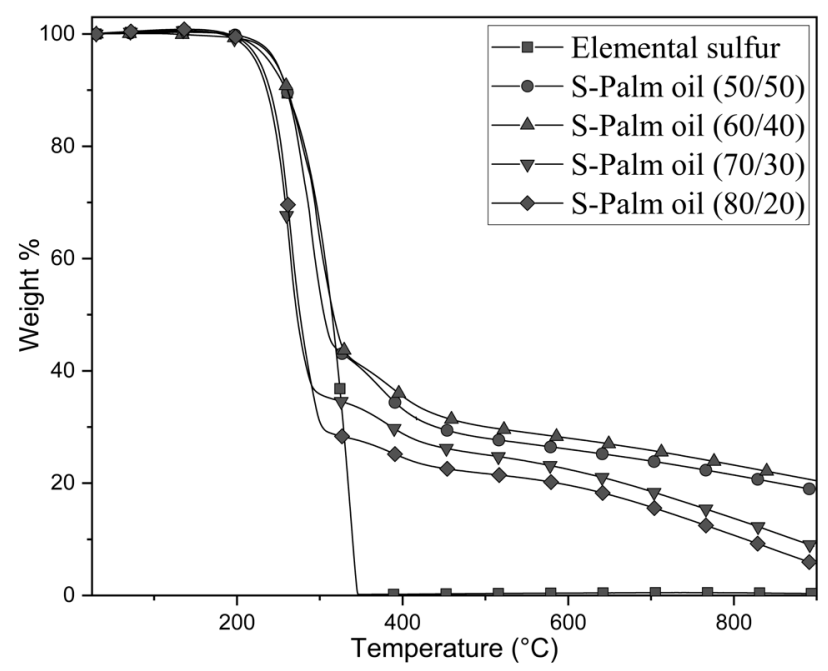

Fig. 2. TGA thermograms for elemental sulfur, and the obtained S-Palm oil copolymers, i.e., 50:50, 60:40, 70:30, and 80:20.

Table 2. TGA coordinates of the obtained polymers at the end of the first degradation step

\begin{tabular}{|c|c|c|c|c|}
\hline $\begin{array}{c}\text { S: Palm } \\
\text { oil } \\
(\mathbf{w} / \mathbf{w} \%)\end{array}$ & $\begin{array}{c}\text { Temperature } \\
\text { at the end of } \\
\text { the first } \\
\text { degradation } \\
\text { step }\left({ }^{\circ} \mathbf{C}\right)\end{array}$ & $\begin{array}{c}\text { Weight loss } \\
\text { \% at the } \\
\text { end of the } \\
\text { first } \\
\text { degradation } \\
\text { step }(\%)\end{array}$ & $\begin{array}{c}\text { Expected } \\
\text { weight loss } \\
\% \text { in case } \\
\text { of full } \\
\text { conversion } \\
\mathbf{( \% )}\end{array}$ & $\begin{array}{c}\text { Ratio of } \\
\text { actual } \\
\text { sulfur } \\
\text { content on } \\
\text { the expected } \\
\text { sulfur } \\
\text { content }\end{array}$ \\
\hline $100: 0$ & 345 & 0 & - & \\
\hline $50: 50$ & 319 & 56 & 50 & 1.12 \\
\hline $60: 40$ & 335 & 58 & 60 & 0.97 \\
\hline $70: 30$ & 291 & 64 & 70 & 0.91 \\
\hline $80: 20$ & 305 & 71 & 80 & 0.89 \\
\hline
\end{tabular}

As it was mentioned earlier, the initial sharp weight loss is due to the actual sulfur content in the polymeric structure. The ratio of the actual sulfur content over the initially added sulfur percentage is considered as an indicator of sulfur conversion compared with palm oil conversion. The ratio higher than one in the case of the 50:50 polymer shows that a big portion of the unsaturated section of palm oil has not taken part in the polymerization process and was wasted with the sludgy phase (mainly consisted of the saturated section of palm oil). However, in the case of the other polymers, it can be seen by increasing the initial sulfur load from 60 to 80 $\mathrm{wt} \%$, the conversion of sulfur decreased compared to that of palm oil.

\subsection{Physical and chemical properties of poly (S- Palm oil)}

The produced copolymers demonstrated brownish color that grew lighter by rising the initial sulfur load. The obtained copolymers also demonstrated no solubility in conventional organic solvents such as toluene, chloroform, ethanol, and 1,4-dioxane. Polymers with weight ratios of sulfur: palm oil of 50:50, 60:40, 70:30, and 80:20 resulted in a homogenous phase forming a rubbery polymer at the end of the reaction. However, by increasing the sulfur load, polymers showed more solidlike behavior. Poly (S-Palm oil) 70:30 showed a good balance between the conversion of sulfur and the physical properties (considering the fact that the stability of the 80:20 polymer against depolymerization was at the edge) and thus was selected for further characterizations.

Figure 3 demonstrates the FTIR spectra of poly (SPalm oil) $70: 30$ together with pure palm oil as a reference.

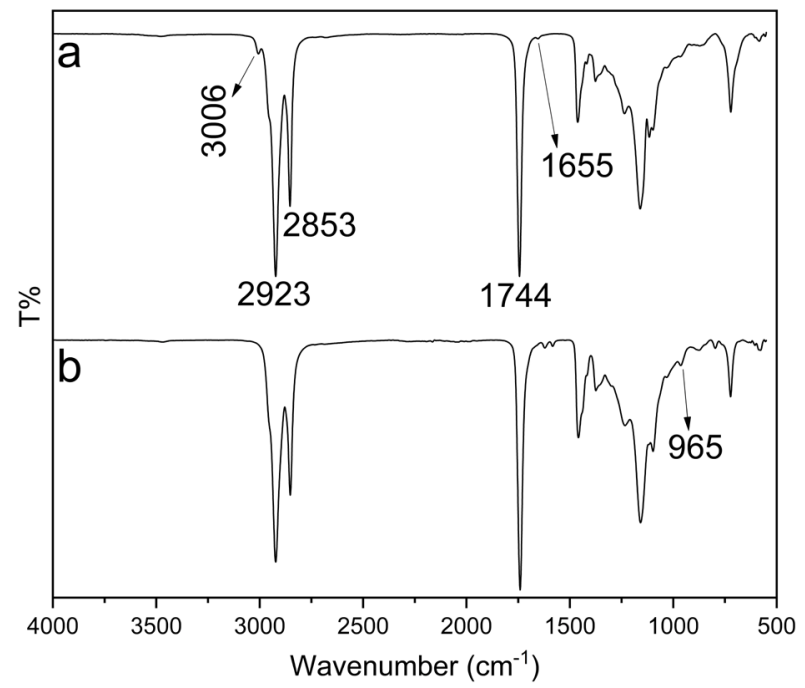

Fig. 3. FTIR spectra for: a) Palm oil, and b) poly (S-Palm oil) 70:30.

Pure palm oil shows a very similar spectrum compared to other vegetable oils in literature due to the composition similarity of different vegetable oil species $[22,33]$. Particularly, palm oil shows a small vinylic $\mathrm{C}=\mathrm{C}$ double bond stretching peak at $1655 \mathrm{~cm}^{-1}$ and vinylic $\mathrm{C}$ - 
$\mathrm{H}$ stretching vibration at $3006 \mathrm{~cm}^{-1}$. These characteristic peaks were not observed for the obtained polymer while the rest of the polymer spectrum showed similar peaks to the spectrum of pure palm oil $[24,26]$. The small peak that appeared for the obtained polymer at $965 \mathrm{~cm}^{-1}$ is due to the $\mathrm{C}-\mathrm{H}$ rocking vibrations which are in the vicinity of C-S bonds [24]. These features confirm the consumption of the $\mathrm{C}=\mathrm{C}$ double bonds of triglycerides reacted with the sulfur chains forming poly (S-Palm oil) $[24,26]$.

\subsection{Thermal properties of poly (S-Palm oil)}

According to literature, the onset of the first degradation step of elemental sulfur is about $210^{\circ} \mathrm{C}$. However, this step takes place sooner for poly (S-Palm oil) 70:30 and $80: 20$ at about $200^{\circ} \mathrm{C}$ and later for 50:50 and 60:40 at about $230^{\circ} \mathrm{C}$ (Figure 2). This change in the weight loss trend for the sulfur-based polymers compared to that of elemental sulfur indicates that a polymeric structure is formed [18]. For different sulfur contents, there are similar weight loss trends with a sharp first degradation step which is due to the sulfur content of the polymer followed by a very small second step and a moderate decrease in the weight percentage afterward $[20,24]$. Spalm oil (50:50) shows a trend similar to S-palm oil (60:40) which may be due to palm oil's content of saturated fatty acids which in result is less likely to result in a uniform polymeric structure in case of high palm oil content polymers.

Figure 4 reports the DSC thermograms of poly (SPalm oil) 70:30 together with fresh pure polysulfur as a reference.

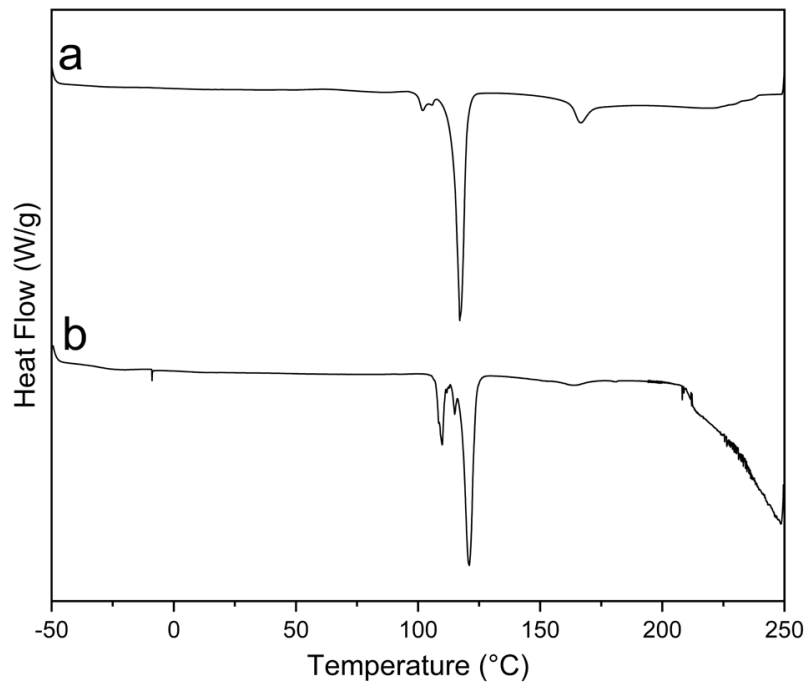

Fig. 4. DSC thermograms for: a) Fresh polysulfur, and b) poly (S-Palm oil) 70:30.

The polysulfur sample was produced using the same reaction conditions $\left(170^{\circ} \mathrm{C}\right.$ and 1 hour); only in this case, no monomer was added to the sulfur melt. This polysulfur was freshly prepared and immediately tested after the polymerization to ensure that the depolymerization of sulfur chains does not happen. The unreacted elemental sulfur shows two peaks at about $109^{\circ} \mathrm{C}$ and $119^{\circ} \mathrm{C}$ which are due to the melting points of different crystalline structures of elemental sulfur
$[34,35]$. These peaks are also visible in the thermograms of poly (S-Palm oil) and polysulfur which indicates that some of the elemental sulfur has not been reacted or reacted and depolymerized although the small shifts in the temperature of the peaks of poly (S-Palm oil) thermogram compared to polysulfur confirm the formation of a polymeric structure of sulfur and palm oil $[18,25,36]$. Poly (S-Palm oil) is rubbery at room temperature and that is the reason why the copolymer demonstrates no glass transition temperature in the temperature range of the experiment since the $\mathrm{T}_{\mathrm{g}}$ for the copolymer must be lower than $-50^{\circ} \mathrm{C}$. Besides, no crystallization or melting peaks related to the copolymer can be observed suggesting an amorphous structure for the poly (S-Palm oil).

\section{Conclusion}

Palm oil was copolymerized with elemental sulfur using a facile process called inverse vulcanization which does not need any catalysts, solvents, or initiators. The ratio of the actual sulfur content in the polymers on the initial sulfur loading was calculated for all the polymers using the TGA thermograms. Poly (S-Palm oil) 70:30 was chosen to be further characterized due to its good balance between conversion and physical properties. Analysis of FTIR spectrum showed disappearance of vinylic peaks and apparition of new peaks, proving the formation of the polymeric structure and the consumption of vinylic groups. TGA thermograms indicated that S-Palm oil copolymers show thermal stability up to $200^{\circ} \mathrm{C}$ (for $70: 30$ and $80: 20$ ) and $230^{\circ} \mathrm{C}$ (for 50:50 and 60:40). All the polymers demonstrated a small difference (less than 10\%) between the sulfur content in the polymer and the initial sulfur content which proves that most of the initial sulfur content has reacted into the polymeric structure. The amorphous structure of poly (S-Palm oil) was verified by DSC analysis with no glass transition temperature was observed for the copolymer in the experiment temperature range. DSC also provided information on the presence of unreacted or depolymerized elemental sulfur in the product. Due to their environmental-friendly nature and lower price, these new green polymers have the potential to be used in different applications such as Li-S batteries and water-treatment adsorbents as a replacement for the conventional petro-based polymers.

The authors wish to thank Universiti Teknologi PETRONAS for supporting this work through YUTP-FRG grant (cost center: 015LC0-065).

\section{References}

1. T. Rocha-Santos and A. C. Duarte, TrAC Trends Anal. Chem. 65, 47 (2015)

2. B. Lochab, I. K. Varma, and J. Bijwe, Adv. Mater. Phys. Chem. 2, 221 (2012)

3. A. Abbasi, M. M. Nasef, and W. Z. N. Yahya, Green Mater. 1 (2020) 
4. S. Miao, P. Wang, Z. Su, and S. Zhang, Acta Biomater. 10, 1692 (2014)

5. J. C. Ronda, G. Lligadas, M. Galià, and V. Cádiz, Eur. J. Lipid Sci. Technol. 113, 46 (2011)

6. A. Abbasi, M. M. Nasef, and W. Z. N. Yahya, Sustain. Chem. Pharm. 13, 100158 (2019)

7. I. E. Henson, in Palm Oil Prod. Process. Charact. Uses (Elsevier Inc., 2012), pp. 1-29

8. A. Mancini, E. Imperlini, E. Nigro, C. Montagnese, A. Daniele, S. Orrù, and P. Buono, Molecules 20, 17339 (2015)

9. (n.d.)

10. Desnelli, D. Mujahidin, Y. Permana, and C. L. Radiman, Procedia Chem. 17, 44 (2015)

11. Y. Xia and R. C. Larock, Green Chem. 12, 1893 (2010)

12. K. Sato, in Palm Oil Prod. Process. Charact. Uses (Elsevier Inc., 2012), pp. 393-429

13. H. Kalita, A. Jayasooriyamu, S. Fernando, and B. J. Chisholm, J. Oil Palm Res. 27, 39 (2015)

14. R. Tajau, R. Rohani, W. N. Roslam, W. Isahak, and M. Z. Salleh, Malaysian J. Anal. Sci. 21, 496 (2017)

15. Z. A. Mas'Ud, M. Farid, H. Surya, and S. Bambang, in IOP Conf. Ser. Mater. Sci. Eng. (2019)

16. J. A. Smith, X. Wu, N. G. Berry, and T. Hasell, J. Polym. Sci. Part A Polym. Chem. 56, 1777 (2018)

17. W. J. Chung, J. J. Griebel, E. T. Kim, H. Yoon, A. G. Simmonds, H. J. Ji, P. T. Dirlam, R. S. Glass, J. J. Wie, N. A. Nguyen, B. W. Guralnick, J. Park, Á. Somogyi, P. Theato, M. E. Mackay, Y.-E. Sung, K. Char, and J. Pyun, Nat. Chem. 5, 518 (2013)

18. D. J. Parker, H. A. Jones, S. Petcher, L. Cervini, J. M. Griffin, R. Akhtar, and T. Hasell, J. Mater. Chem. A 5, $11682(2017)$

19. M. P. Crockett, A. M. Evans, M. J. H. Worthington, I. S. Albuquerque, A. D. Slattery, C. T. Gibson, J. A. Campbell, D. A. Lewis, G. J. L. Bernardes, and J. M. Chalker, Angew. Chemie Int. Ed. 55, 1714 (2016)

20. I. Gomez, O. Leonet, J. A. Blazquez, and D. Mecerreyes, ChemSusChem 9, 3419 (2016)

21. D. J. Parker, S. T. Chong, and T. Hasell, RSC Adv. 8, 27892 (2018)

22. A. S. M. Ghumman, M. R. Shamsuddin, M. M. Nasef, W. Z. N. Yahya, M. Ayoub, B. Cheah, and A. Abbasi, ChemistrySelect 6, 1180 (2021)

23. A. S. M. Ghumman, R. Shamsuddin, M. M. Nasef, W. Z. N. Yahya, and A. Abbasi, Polymer (Guildf). 219, 123553 (2021)

24. A. Hoefling, Y. J. Lee, and P. Theato, Macromol. Chem. Phys. 218, 1600303 (2017)

25. M. J. H. Worthington, R. L. Kucera, I. S. Albuquerque, C. T. Gibson, A. Sibley, A. D. Slattery, J. A. Campbell, S. F. K. Alboaiji, K. A. Muller, J. Young, N. Adamson, J. R. Gascooke, D. Jampaiah, Y. M. Sabri, S. K. Bhargava, S. J. Ippolito, D. A. Lewis, J. S. Quinton, A. V. Ellis, A. Johs, G. J. L. Bernardes, and J. M. Chalker, Chem. - A Eur. J. 23, 16219 (2017)

26. S. F. Valle, A. S. Giroto, R. Klaic, G. G. F. Guimarães, and C. Ribeiro, Polym. Degrad. Stab. 162, 102 (2019)

27. J. J. Griebel, R. S. Glass, K. Char, and J. Pyun, Prog. Polym. Sci. 58, 90 (2016)

28. J. M. Chalker, M. J. H. H. Worthington, N. A. Lundquist, and L. J. Esdaile, Synthesis and Applications of Polymers Made by Inverse Vulcanization (Springer International Publishing, 2019), p. 16

29. A. Abbasi, M. M. Nasef, W. Z. N. Yahya, M. Moniruzzaman, and A. S. M. Ghumman, Eur. Polym. J. 143, 110202 (2021)

30. J. Liu, B. Campbell, R. Ye, J. Bell, Z. Mutlu, C. Li, Y. Yan, M. Ozkan, and C. Ozkan, MRS Adv. 2, 3271 (2017)

31. A. Hoefling, D. T. Nguyen, Y. J. Lee, S.-W. Song, and P. Theato, Mater. Chem. Front. 1, 1818 (2017)

32. P. T. Dirlam, A. G. Simmonds, T. S. Kleine, N. A. Nguyen, L. E. Anderson, A. O. Klever, A. Florian, P. J. Costanzo, P. Theato, M. E. Mackay, R. S. Glass, K. Char, and J. Pyun, RSC Adv. 5, 24718 (2015)

33. A. Abbasi, M. M. Nasef, W. Z. N. Yahya, M. Moniruzzaman, and A. S. Ghumman, Polym. Polym. Compos. 096739112095953 (2020)

34. L. Zhang, Y. Ren, X. Liu, F. Han, K. Evans-Lutterodt, H. Wang, Y. He, J. Wang, Y. Zhao, and W. Yang, Sci. Rep. 8, 1 (2018)

35. J. Moon, P. D. Kalb, L. Milian, and P. A. Northrup, Cem. Concr. Compos. 67, 20 (2016)

36. M. Arslan, B. Kiskan, E. C. Cengiz, R. Demir-Cakan, and Y. Yagci, Eur. Polym. J. 80, 70 (2016) 